WellBeing International

WBI Studies Repository

$12-2007$

\title{
Heritable and Experiential Effects on Boldness in a Tropical Poeciliid
}

\author{
Culum Brown \\ Macquarie University \\ Fiona Burgess \\ University of Edinburgh \\ Victoria Braithwaite \\ University of Edinburgh
}

Follow this and additional works at: https://www.wellbeingintlstudiesrepository.org/acwp_asie

Part of the Animal Studies Commons, Comparative Psychology Commons, and the Other Animal Sciences Commons

\section{Recommended Citation}

Brown, C., Burgess, F., \& Braithwaite, V. A. (2007). Heritable and experiential effects on boldness in a tropical poeciliid. Behavioral Ecology and Sociobiology, 62(2), 237-243.

This material is brought to you for free and open access by WellBeing International. It has been accepted for inclusion by an authorized administrator of the WBI Studies Repository. For more information, please contact wbisr-info@wellbeingintl.org.

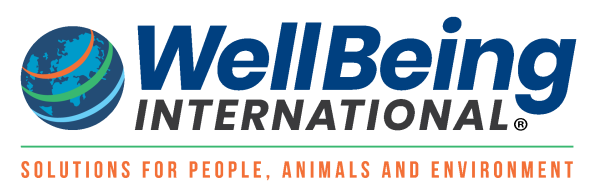




\title{
Heritable and Experiential Effects on Boldness in a Tropical Poeciliid
}

\author{
Culum Brown, ${ }^{1}$ Fiona Burgess, ${ }^{2}$ and Victoria A. Braithwaite ${ }^{2}$ \\ ${ }^{1}$ Macquarie University \\ ${ }^{2}$ University of Edinburgh
}

KEYWORDS

boldness-shyness, personality, heritability, environment, predation, poeciliid

\begin{abstract}
Consistent differences in human behaviour are often explained with reference to personality traits. Recent evidence suggests that similar traits are widespread across the entire animal kingdom and that they may have substantial fitness consequences. One of the major components of personality is the shynessboldness continuum. Little is known about the relative contributions of genes and the environment in the development of boldness in wild animal populations. Here, we bred wild-caught fish (Brachyraphis episcopi) collected from regions of highand low-predation pressure, reared their offspring in the laboratory under varying conditions and tested boldness utilising an open-field paradigm. First-generation laboratory-reared fish showed similar behaviour to their wild parents suggesting that boldness has a heritable component. In addition, repeated chasing with a net increased boldness in both high- and lowpredation offspring, showing that boldness is also heavily influenced by life experiences. Differences between males and females were also sustained in the laboratory-reared generation indicating that sex differences in boldness are also heritable. We discuss these results with reference to the potential underlying genetic and hormonal mechanisms as well as the environmental influences that may be responsible for expression of boldness in wild animals.
\end{abstract}

\section{Introduction}

In recent years, it has emerged that personality traits used to describe and quantify behavioural variation in humans also exist in the rest of the animal kingdom (Boissy 1995; Gosling 2001; Sih et al. 2004). One major component of personality is the shyness-boldness continuum. Bold individuals tend to be risk takers and are quick to approach novel objects and explore novel environments. In contrast, shy individuals tend to be risk averse and are generally neophobic (Wilson et al. 1994). Behaviour of shy individuals in novel situations is often accompanied by fear responses, such as freezing (Brown and Smith 1996; Budaev et al. 1999a, b; Templeton and Shriner 2004). But how do such traits arise?

Recent investigations suggest that variation in individual behaviour may not be randomly scattered around a locally adaptive behavioural average, rather, they represent adaptive individual behavioural strategies (Dall et al. 2004; Brown et al. 2007). Individual variation in the behaviour of animals can often 
be predicted by examining demographic variables (e.g. size, age or sex) or intrinsic factors (or states) including hunger or reproductive status (Wilson et al. 1994). Nevertheless, even after such variables are considered, individuals display consistent behavioural differences across a range of circumstances or contexts which is characteristic of personality traits (Gosling 2001). The fitness value of expressing alternative behavioural strategies is already widely accepted by evolutionary biologists (e.g. sneaky mating tactics in guppies, Evans et al. 2003; satellite males in frogs, Leary et al. 2005), yet the expression of personality traits is seldom investigated within a similar evolutionary framework (Dingemanse et al. 2003). The expression of particular personality traits may have considerable ecological and evolutionary consequences, especially when the fitness of an individual is strongly dependent on the expression of a behavioural phenotype within a given environmental context. We have already shown that fishes in highpredation areas tend to behave more boldly than their low-predation counterparts (Brown et al. 2005b), and the position of an individual along the shyness-boldness axis is highly correlated with fitness (i.e. condition factor; Brown et al. 2007). Other experiments suggest that boldness is also associated with variance in parasite load, foraging behaviour, mate choice, parental care, reproductive success, dispersal, anti-predator behaviour, invasion or colonisation ability and speciation potential (Coleman and Wilson 1998; Godin and Dugatkin 1996, Budaev et al. 1999a, b; Reale et al. 2000; Godin and Davis 1995; Martin and Fitzgerald 2005).

Human personality traits are known to have both heritable and environmental components, although the exact proximate causes of the expression of different personality traits are still regularly debated (McGue and Bouchard 1998). The ultimate causes are seldom discussed and rarely investigated (Groothuis and Carere 2005). Recent observations suggest that traits such as boldness may also have a heritable component in animals (van Oers et al. 2004). Given its association with fitness traits, the expression of boldness is likely to be under heavy selective pressure and ought to change depending on the environment an animal occupies. One would expect, therefore, that boldness is shaped by geneenvironment interactions, and relative strength of each component is likely to vary between populations. Little is known about how early experience influences the development of boldness in wild animals, although early work on captive populations of primates and rodents suggests that it is likely to be substantial (Harlow and Harlow 1965; Hinde 1974; Cameron et al. 2005). For example, a selection pressure as unforgiving as predation is likely to influence the distribution of bold and shy individuals, but do these differences arise through heritable differences or because of the environment the animals experience as they develop?

We have been working on a series of studies with a small tropical poeciliid, the Panamanian bishop (Brachyraphis episcopi), that is naturally distributed between sites that differ in predation pressure. $B$. episcopi are live-bearers that primarily feed on terrestrial insects and are widely distributed in the headwater streams of Panama. These fish provide an excellent system in which to investigate how boldness varies under contrasting levels of selection pressure (Brown and Braithwaite 2004; Brown et al. 2005b; Brown et al. 2007). Fish from high-predation areas emerge from shelter sooner, are more likely to leave shoal mates investigate novel objects and are, therefore, generally bolder than those from lowpredation areas, and this difference is most pronounced in males (Brown et al. 2005b, Brown et al. 2007). Fish in high-predation areas must be able to carry on with normal activities (e.g. foraging and courtship) despite the present risk of death by predators; hence, selection favours bold individuals in these regions. No such selective pressure exists in low-predation areas. There is, however, some debate as to the exact causal factor responsible for behavioural shifts between high- and low-predation areas (Arendt and Reznick 2005) so controlled experimental studies are warranted. Here, we use a controlled rearing approach to determine to what extent these population and sex difference arise during ontogeny as a result of experience and whether they have heritable genetic components. 


\section{Materials and methods}

We captured fish from sites of high- and low-predation pressure in each of three geographically separated streams (QJG, RM and RL) using hand-held dip nets (ANAM permit\# 31503). Each stream contains a waterfall barrier that prevents the upstream movement of the majority of the fish fauna. Above the falls, the fauna consists almost entirely of our study species, B. episcopi and the occasional killifish (Rivulus brunnei). Both $B$. episcopi and $R$. brunnei exist below the falls; however, these areas are mostly dominated by a variety of piscine predators and tetras (family Charicidae; see Brown and Braithwaite 2004 for further details). The three streams run independently into the Panama Canal, and the distribution of $B$. episcopi does not extend to the lower reaches of the streams. Fifty females and ten males from each site (6 populations: 360 fish total) were transported to our laboratories at the University of Edinburgh, where they were established in separate $90 \times 30 \mathrm{~cm}$ aquaria for each site. Each aquarium was furnished with river gravel, rocks, artificial plants and an internal power filter. The room was heated to $25^{\circ} \mathrm{C}$, and lighting was maintained on a 12-h light/dark cycle. Owing to the aggressive nature of both males and females, only two males could be housed with the females at any one time. All ten males were given an opportunity to court and mate with the females from their population. Fish were maintained on a commercial tropical flake food diet supplemented with live food (blood worm, brine shrimp, tubifex and daphnia). Pregnant females were removed from the general population and isolated in small aquaria equipped with fry-traps. Most females produced offspring in this way and contributed to the lab-reared generation. Fry were housed in tanks similar to those of the adults and maintained on live-bearing liquid fry food and finely crushed flake food. Juvenile males were removed and housed separately as soon as they were identified by the developing gonopodium.

Upon reaching 25-mm standard length, lab-reared females were exposed to one of two treatments. In the first treatment, the fish remained undisturbed in their home tanks, whilst in the second, they were housed in small groups in plastic aquaria $(25 \mathrm{~cm}$ long $\times 40 \mathrm{~cm}$ wide $\times 20 \mathrm{~cm}$ deep) and exposed to simulated predator attack by chasing them with a dip net for 2 min, every day for 2 weeks. The net was moved in such a way as to ensure that every fish was chased during the 2-min time period. Lab-reared males were left undisturbed in their home tanks. At the end of the 2-week period $(2 \mathrm{~h}$ after the final net chase for fish in the chased treatment), the fish were gently transferred from their respective aquaria to a box in the experimental arena. The arena consisted of a glass aquarium $(60 \times 60 \mathrm{~cm})$, the outer sides of which were wrapped in black plastic, although the top was open to allow access and light to penetrate. Lighting was provided by over-head fluorescent tubes; however, the light did not shine directly into the test arena. Water depth was maintained at $10 \mathrm{~cm}$. The arena was furnished with river gravel, plastic plants, rocks and a corner air stone. A start box $(19 \mathrm{~cm}$ high $\times 8 \mathrm{~cm}$ wide $\times 10 \mathrm{~cm}$ long $)$ constructed from grey plastic was positioned upon a white plastic semi-circle on one side of the arena. The box was equipped with a vertically sliding trapdoor $(3 \times 3 \mathrm{~cm})$ that could be opened and closed via a remote pulley system (Fig. 1; see Brown et al. 2005b for more details). On the opposite wall of the arena to the start box, a small slit was made in the outer plastic to enable us to observe the fish, without disturbing them.

Each fish was placed into the start box and allowed to settle for 2 min before the sliding door was raised remotely. The time taken for the fish to emerge from the box and explore the novel arena was recorded as an assay of boldness (Brown and Braithwaite 2004; Brown et al. 2005b; Brown et al. 2007). This measure of boldness is analogous to the widely utilised open-field test (e.g. Kilgour 1975; Yoshida et al. 2005) and is highly correlated with other assays of boldness (Brown et al. 2007). We tested a total of 81 F1 females from high- and low-predation areas (30 undisturbed and 51 chased by the net). In addition, a further 48 undisturbed males were tested to enable a comparison of boldness between sexes. In total, we utilised 66 fish from QJG, 37 from RL and 26 from RM. The data from each of the three streams were pooled owing to an incomplete matrix because some of the populations proved more difficult to breed 
than others (we lacked lab-reared fish in the RL, low-predation, undisturbed treatment). However, an analysis of variance (ANOVA) on the complete data set showed no effect of river on time to emerge from the box $\left(F_{2,126}=0.497, p=0.609\right)$. Due to deviances from normal, the data were logged transformed before analysis using ANOVA.
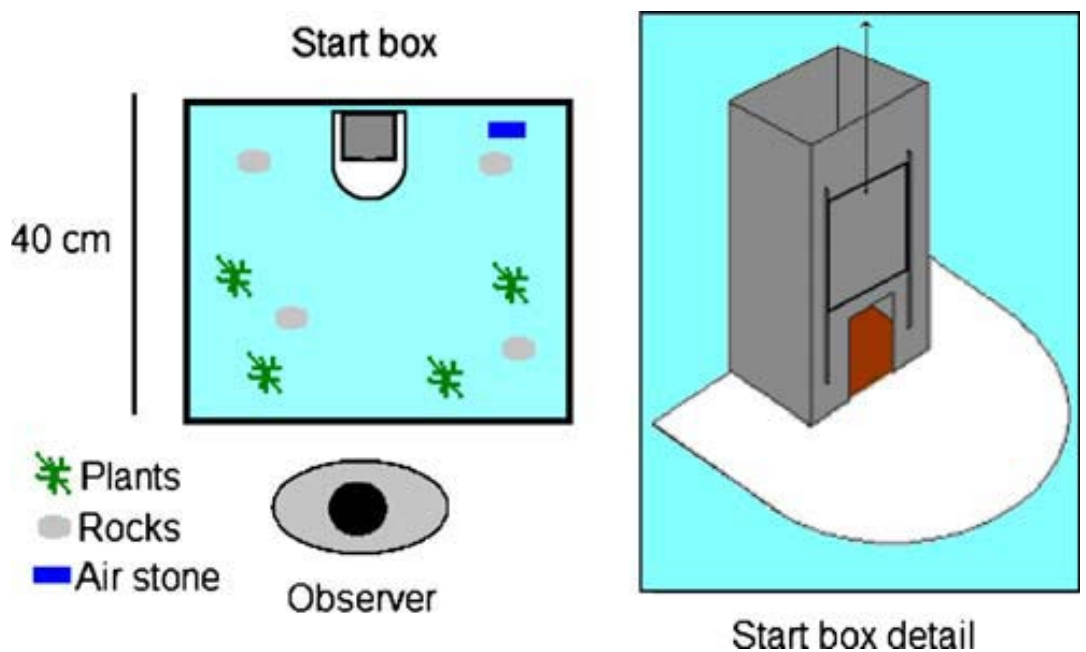

Fig. 1 A diagrammatic representation of the test arena on the left and details of the start box on the right

\section{Results}

Our ANOVA revealed that laboratory-reared fish with parents from high-predation areas emerged significantly faster from shelter to explore the novel environment than lab-reared fish with low-predation parents $\left(F_{1,77}=5.85, p=0.018\right.$; Fig. 2$)$. Fish that had been repeatedly chased by a net were significantly bolder than those that remained undisturbed $\left(F_{1,77}=42.74, p<0.001\right.$; Fig. 2). The interaction between the disturbance and predation regimes was not significant $(F 1,77=0.31, p=0.579)$. Note that more variance in boldness score was generated by chasing the fish with the net rather than the parental predator regime. This is confirmed by an effect size analysis based on pooled standard deviations (Oakes 1986), where the effect size of parental origin was 0.25 compared to 1.01 due to disturbance regime. Examination of undisturbed lab-reared males and females revealed that males emerge from shelter significantly faster than females $\left(F_{1,76}=280.75, p<0.001 ;\right.$ Fig. 3$)$.

\section{Discussion}

Population differences in boldness traits between high- and low-predation fish appear to have both experiential and heritable components, although maternal effects cannot be ruled out. Laboratory-reared females bred from wild-caught, high-predation fish were significantly bolder than lab-reared females with parents from low-predation areas. Although our methodology did not allow the estimation of heritability, the difference between the lab-reared high- and low-predation juveniles was of a similar magnitude to that observed in the wild-caught parental generation in previous studies (Brown et al. 2005b; Brown et al. 2007). In addition, lab-reared females that had experienced being chased by a net before testing were bolder than fish that remained undisturbed, indicating that boldness is also influenced by experience during ontogeny. In addition, boldness of both high- and low-predation lab-reared fish was equally susceptible to environmental influences, with both high- and low-predation fish increasing their boldness 
after being repeatedly chased by a net. The open-field test utilised here is a widely used assay of boldness (Kilgour 1975; Yoshida et al. 2005), and previous experiments have shown that there is a high correlation between this and other boldness assays such as the propensity to approach novel objects in B. episcopi (Brown et al. 2007). When taken together, these results show that an individual's position on the boldness-shyness continuum is influenced by both environmental and genetic factors.

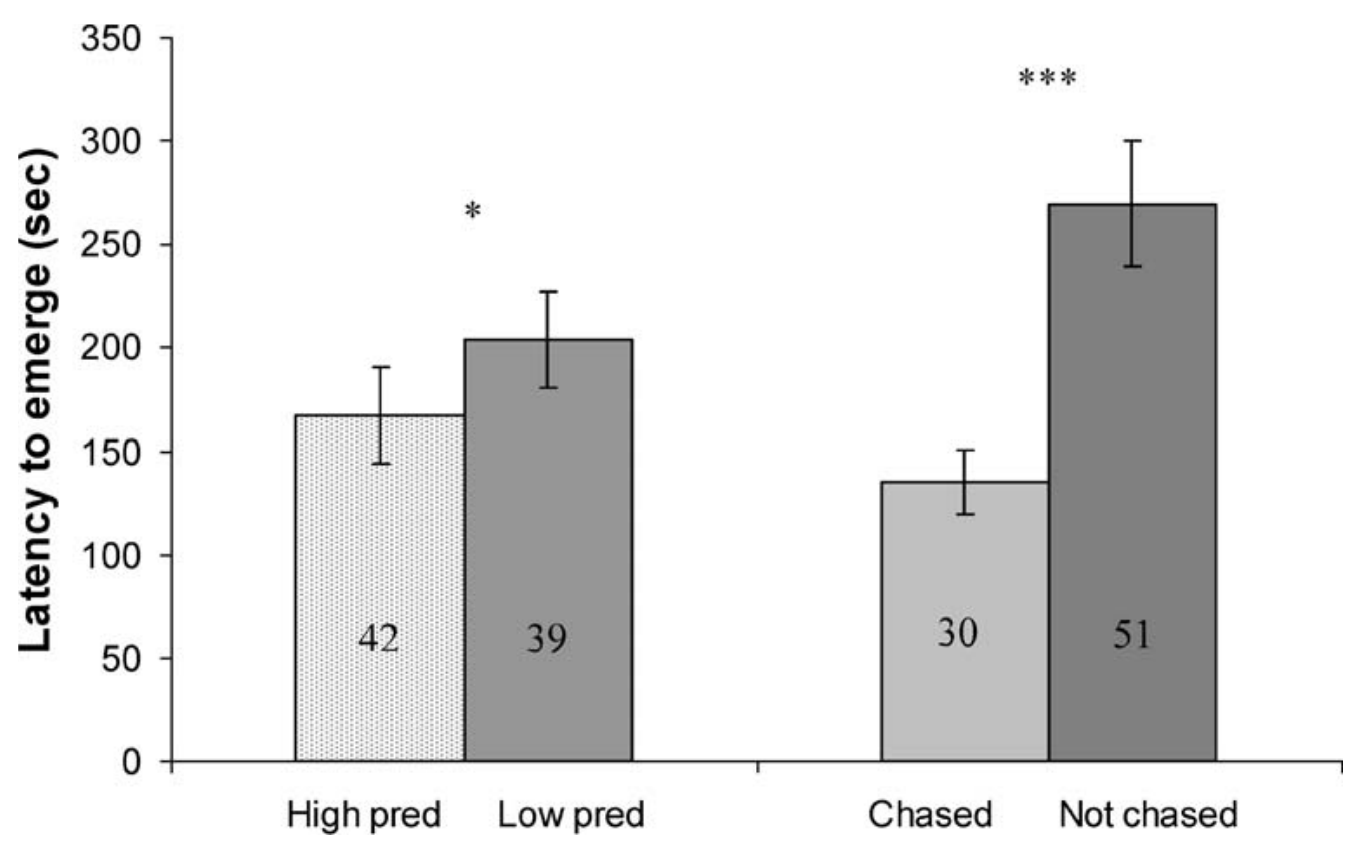

Fig. 2 The mean ( $\pm S E$ ) time to emerge from the shelter and begin to explore a novel environment for laboratory-reared F1 females of parents captured in high- and low-predation sites and F1s that were chased with a net or not. ${ }^{*} p<0.05,{ }^{* * *} p<0.001$, ANOVA performed on log transformed data (see text for details). Numbers in each column represent $n$ values

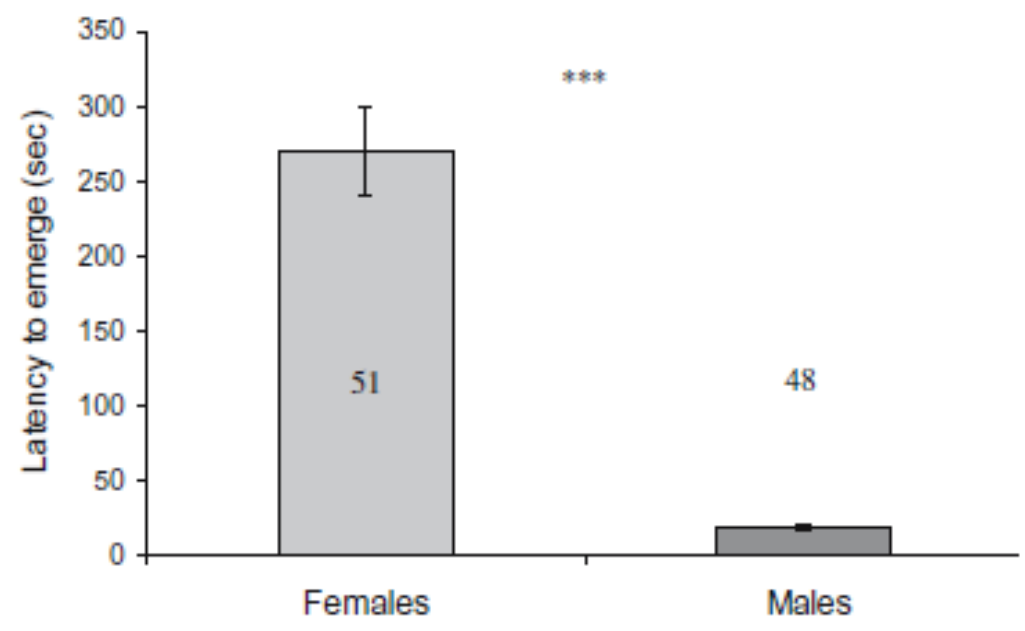

Fig. 3 The mean ( \pm SE) time taken for females and males that had not been chased to emerge from shelter and enter a novel environment. ${ }^{* *} p<0.001$, ANOVA performed on log transformed data (see text for details). Numbers in each column represent $n$ values 
Previous experiments (Brown et al. 2005a, 2007) conducted on fish collected in the wild revealed that males were faster to emerge from cover (bolder) than females. Here, we show that these differences between the sexes are maintained in the first laboratory-reared generation. This suggests that boldnessshyness differences between the sexes can be partially explained by genetic influences and are probably mediated via hormonal expression. Similar differences between the sexes have been made in rats using a novelty-seeking paradigm (Ray and Hansen 2004). Experiments conducted on quail have revealed that the level of testosterone present in the embryo can have a significant influence on behaviour phenotype. Quail chicks that had $50 \mathrm{ng}$ of testosterone injected into their yolk were more likely to approach novel objects compared to sham injected chicks, and the treatment affected both sexes equally (Daisley et al. 2005). In the future, QTL mapping may identify genes strongly associated with boldness in our experimental populations (Wright et al. 2006). This approach has been used successfully by Gershenfeld et al. (1997) where markers associated with a number of different exploratory behaviours in mice have been identified on several different chromosomes. We hypothesise that the candidate genes for boldness-shyness are likely to be associated with stress responses (such as the hypothalamic-pituitaryinterrenal axis in fish and the homologous mammalian hypothalamic-pituitary-adrenal axis). Evidently, further progress could be gained by conducting hormone analyses.

If individual differences in behaviour are linked to variation in the levels of circulating hormones, it is possible that the differences observed in our lab-reared fish may result from maternal effects (Cameron et al. 2005). B. episcopi are ovoviviparous, so the potential for maternal effects on behavioural variance is high and can potentially inflate estimates of heritability (Kruuk et al. 2000). We are unable to separate variance due to maternal effects from that directly influenced by an individual's genes. Recent analysis of salt water tolerance in guppies found no evidence of maternal effects (Shikano and Fujio 1998); however, Reznick et al. (1996) found evidence for the effects of maternal provisioning on offspring quality. Pedigree analysis or cross-classified breeding experiments involving multiple matings between individual males and females would enable the variance between these two factors to be partitioned and remains an objective for future work.

Whilst our understanding of the potential genetic influences of the expression of boldness steadily grows, less is known about experience on the development of behavioural phenotypes. It is evident from our experiments that repeated exposure to potentially threatening stimuli (in the form of repeated chasing with a dip net) over a relatively short time frame had a significant influence on individual's position on the shyness-boldness continuum. Similar observations have been made in lizards repeatedly exposed to simulated predator attacks (Lopez et al. 2005). Early experiences in domesticated animals, particularly before or during the weaning process, can have substantial long-term influences on individual behaviour. For example, both breed and pre-weaning social conditions influence the expression of fear in sheep and horses (Romeyer and Bouissou 1992; Lansade et al. 2004). These results with domestic animals mirror those obtained in lab strains of mice and rhesus monkeys (Clarke 1993; Caldji et al. 2000). Mice that are repeatedly handled for $15 \mathrm{~min}$ in the first 14 days of life show reduced stress responses as adults (Caldji et al. 2000). Whilst the behaviour of the fish in response to being repeatedly frightened by either a net, as was the case here, or by predators, as would be the case in the wild, seems counter-intuitive, our results fit well with previous studies, particularly those conducted on rodents. Whilst frightening or stressful experiences that occur very rarely might have the effect of increasing shyness, long-term, repeated exposure seems to have just the opposite effect. Over time, the animals learn to adjust to these situations, and adjustments probably occur at both the psychological and physiological levels (Caldji et al. 2000; Cameron et al. 2005). We have already shown that our populations differ dramatically in their response to mildly stressful stimuli as indicated by opercula beat activity (Brown et al. 2005a), although we are yet to determine how these population differences are maintained and if stress responses are heritable. 
While a great deal is known about the proximate causes of individual differences in model organisms such as rodents (Cameron et al. 2005), we still know relatively little about the ultimate explanations of individual differences. We have recently shown that the expression of boldness influences a fitnessrelated trait in body condition (Brown et al. 2007) which indicates that the behavioural strategies individuals adopt are under heavy selective pressure that varies depending on the environment the animals occupy. However, boldness may have other, more subtle fitness-related consequences that have yet to be explored. For example, research conducted on guppies has shown that females prefer to mate with bold males (as defined by their tendency to approach predators) and that male boldness is highly correlated with bright pigmentation (Godin and Dugatkin 1996). Both pigmentation pattern and boldness are heritable and may be linked in some way. Thus, boldness may be an honest indicator of an individual's fitness. From this, and based on the results presented herein, we predict that it may be more important for females to select bolder male partners in high- rather than low-predation environments. Moreover, bold males are likely to gain greater access to females than shy males particularly in highpredation locations and thus obtain higher reproductive success (Evans et al. 2003).

One of the fundamental problems with studies of boldness-shyness in animals has been the lack of accepted terminology and methodology. For example, there are a wide number of assays that have been used to record boldness in fishes, and boldness itself has been variously described to match the imposed methodologies (a kind of circularity; e.g. tendency to inspect predators, Godin and Dugatkin 1996; foraging under predation risk, Magnhagen 2006; response to a novel object, Sundstrom et al 2004; openfield test, Budaev 1999b). One of the greatest benefits behavioural ecology can provide to the study of personality is the imposition of a rigorous comparative method. One of the things that this approach stresses is that the assay employed must be equally applicable to all test subjects. With this in mind, it is clear that one could not legitimately measure boldness traits by, for example, examining the behaviour of individuals in the presence of predators owing to differential perception of threat. Predator allopatric individuals, for example, may not categorise predators as a threat, whereas predator sympatric individuals would. Such comparisons examine variation in threat recognition, but they cannot measure boldness (a behavioural response to a set level of risk). Issues such as these highlight the need for a well-defined approach to studying personality traits in animals and explain the widespread use of neutral tests such as the open-field assay.

A recent meta-analysis conducted on the environmental influences of personality differences in humans concluded that such influences are likely to be highly complex (Turkheimer and Waldron 2000). Nevertheless, studies based on the analysis of homozygotic twins and adoption studies have made considerable advances in recent years (Bouchard and McGue 2003). Studying environmental influences on human personality traits is, for obvious reasons, a complicated matter. Unlike humans, individual animals can easily be reared under controlled conditions. Individual experiences can be manipulated, selective crosses can be performed and populations monitored for multiple generations. The fitness benefits associated with certain personalities can also be assessed by directly measuring reproductive success. In this manner, we can approach the study of personality within an evolutionary framework and begin to understand the fitness consequences of expressing different personality traits in a range of environmental contexts (Brown et al. 2007). Thus, in many ways, animal model systems are superior to their human counterparts and have a lot to offer in terms of investigating the environmental and genetic influences on the development of personality traits (Gosling 2001).

\section{Acknowledgement}

We thank the Smithsonian Tropical Research Institute for their continued support, The Darwin Workshop and Felicity Brown for her help in collecting the fish. This work was funded by NERC grant no. 
NER/A/S/01/00608, and experiments conducted herein were conducted in accordance with the Guidelines for the Treatment of Animals in Behavioural Research and Teaching.

\section{References}

Arendt JD, Reznick DN (2005) Evolution of juvenile growth rates in female guppies (Poecilia reticulata): predator regime or resource level. Proc R Soc Lond B Biol Sci 272:333-337

Boissy A (1995) Fear and fearfulness in animals.Q Rev Biol 70:165-191

Bouchard TJ, McGue M (2003) Genetic and environmental influences on human psychological differences. J Neurobiol 54:4-45

Brown G, Smith R (1996) Foraging trade-offs in fathead minnows (Pimephales promelas, Osteichthyes, Cyprinidae): acquired predator recognition in the absence of an alarm response. Ethology 102:776-785

Brown C, Braithwaite VA (2004) Size matters: a test of boldness in eight populations of bishop, Brachyraphis episcopi. Anim Behav 68:1325-1329

Brown C, Gardener C, Braithwaite VA (2005a) Differential stress responses in fish from areas of highand low-predation pressure. J Comp Physiol B 175:305-312

Brown C, Jones F, Braithwaite VA (2005b) In situ examination of boldness-shyness traits in the tropical poeciliid, Brachyraphis episcopi. Anim Behav 70:1003-1009

Brown C, Jones FC, Braithwaite VA (2007) Correlation between boldness and body mass in natural populations of the poeciliid Brachyraphis episcopi. J Fish Biol (in press)

Budaev SV, Zworykin DD, Mochek AD (1999a) Individual differences in parental care and behaviour profile in the convict cichlid: a correlation study. Anim Behav 58:195-202

Budaev SV, Zworykin DD, Mochek AD (1999b) Consistency of individual differences in behaviour of the lion-headed cichlid, Steatocranus casuarius. Behav Processes 48:49-55

Caldji C, Francis D, Sharma S, Plotsky PM, Meaney MJ (2000) The effects of early rearing environment on the development of GABA(A) and central benzodiazepine receptor levels and novelty-induced fearfulness in the rat. Neuropsychopharmacology 22:219-229

Cameron NM, Champagne FA, Fish C, Ozaki-Kuroda K, Meaney MJ (2005) The programming of individual differences in defensive responses and reproductive strategies in the rat through variations in maternal care. Neurosci Biobehav Rev 29:843-865

Clarke AS (1993) Social rearing effects on HPA axis activity over early development and in response to stress in Rhesus monkeys. Dev Psychobiol 26:433-446

Coleman K, Wilson DS (1998) Shyness and boldness in pumpkinseed sunfish: individual differences are context-specific. Anim Behav 56:927-936

Daisley JN, Bromundt V, Mostl E, Kotrschal K (2005) Enhanced yolk testosterone influences behavioral phenotype independent of sex in Japanese quail chicks Coturnix japonica. Horm Behav 47:185194

Dall SRX, Houston AI, McNamara JM (2004) The behavioural ecology of personality: consistent individual differences from an adaptive perspective. Ecol Lett 7:734-739

Dingemanse NJ, Both C, van Noordwijk AJ, Rutten AL, Drent PJ (2003) Natal dispersal and personalities in great tits (Parus major). Proc R Soc Lond B Biol Sci 270:741-747

Evans JP, Pilastro A, Ramnarine IW (2003) Sperm transfer through forced matings and its evolutionary implications in natural guppy (Poecilia reticulata) populations. Biol J Linn Soc 78:605-612

Gershenfeld HK, Neumann PE, Mathis C, Crawley JN, Li XH, Paul SM (1997) Mapping quantitative trait loci for open-field behavior in mice. Behav Genet 27:201-210 
Godin JGJ, Davis SA (1995) Who dares, benefits-predator approach behavior in the guppy (Poecilia reticulata) deters predator pursuit. Proc $\mathrm{R}$ Soc Lond B Biol Sci 259:193-200

Godin JGJ, Dugatkin LA (1996) Female mating preference for bold males in the guppy, Poecilia reticulata. Proc Natl Acad Sci U S A 93:10262-10267

Gosling SD (2001) From mice to men: what can we learn about personality from animal research. Psychol Bull 127:45-86

Groothuis TGG, Carere C (2005) Avian personalities: characterization and epigenesis. Neurosci Biobehav Rev 29:137-150

Harlow HF, Harlow MK (1965) The affectional systems. In: Schrier AM, Harlow HF, Stollnitz F, Behaviour of non-human primates. Academic, New York, pp 287-334

Hinde RA (1974) Biological basis of human social behaviour. McGraw-Hill, New York

Kilgour R (1975) Open-field test as an assessment of temperament of dairy-cows. Anim Behav 23:615624

Kruuk LEB, Clutton-Brock TH, Slate J, Pemberton JM, Brotherstone S, Guinness FE (2000) Heritability of fitness in a wild mammal population. Proc Natl Acad Sci U S A 97:698-703

Lansade L, Bertrand M, Boivin X, Bouissou MF (2004) Effects of handling at weaning on manageability and reactivity of foals. Appl Anim Behav Sci 87:131-149

Leary CJ, Fox DJ, Shepard DB, Garcia AM (2005) Body size, age, growth and alternative mating tactics in toads: satellite males are smaller but not younger than calling males. Anim Behav 70:663-671

Lopez P, Hawlena D, Polo V, Amo L, Martin J (2005) Sources of individual shy-bold variations in antipredator behaviour of male Iberian rock lizards. Anim Behav 69:1-9

Magnhagen C (2006) Risk-taking behaviour in foraging young-of-the-year perch varies with population size structure. Oecologia 147:734-743

Martin LB, Fitzgerald L (2005) A taste for novelty in invading house sparrows, Passer domesticus. Behav Ecol 16:702-707

McGue M, Bouchard TJ (1998) Genetic and environmental influences on human behavioral differences. Ann Rev Neurosci 21:1-24

Oakes M (1986) Statistical inference: A commentary for the social and behavioral sciences. Wiley, New York

Ray J, Hansen S (2004) Temperament in the rat: sex differences and hormonal influences on harm avoidance and novelty seeking. Behav Neurosci 118:488-497

Reale D, Gallant BY, Leblanc M, Festa-Bianchet M (2000) Consistency of temperament in bighorn ewes and correlates with behaviour and life history. Anim Behav 60:589-597

Reznick D, Callahan H, Llauredo R (1996) Maternal effects on offspring quality in poeciliid fishes. Am Zool 36:147-156

Romeyer A, Bouissou MF (1992) Assessment of fear reactions in domestic sheep, and influence of breed and rearing conditions. Appl Anim Behav Sci 34:93-119

Shikano T, Fujio Y (1998) Maternal effect on salinity tolerance in newborn guppy Poecilia reticulata. Fish Sci 64:52-56

Sih A, Bell AM, Johnson JC, Ziemba RE (2004) Behavioral syndromes: an integrative overview. Q Rev Biol 79:241-277

Sundstrom LF, Petersson E, Hojesjo J, Johnsson JI, Jarvi T (2004) Hatchery selection promotes boldness in newly hatched brown trout (Salmo trutta): implications for dominance. Behav Ecol 15:192-198

Templeton CN, Shriner WM (2004) Multiple selection pressures influence Trinidadian guppy (Poecilia reticulata) antipredator behavior. Behav Ecol 15:673-678

Turkheimer E, Waldron M (2000) Nonshared environment: a theoretical, methodological, and quantitative review. Psychol Bull 126:78-108

van Oers K, Drent PJ, de Goede P, van Norrdwijk AJ (2004) Realized heritability and repeatability of risktaking behaviour in relation to avian personalities. Proc R Soc Lond B 271:65-73 
Wilson DS, Clark AB, Coleman K, Dearstyne T (1994) Shyness and boldness in humans and other animals. Trends Ecol Evol 9:442-446

Wright D, Nakamichi R, Krause J, Butlin R (2006) QTL analysis of behavioral and morphological differentiation between wild and laboratory zebrafish (Danio rerio). Behav Genet 36:271-284

Yoshida M, Nagamine M, Uematsu K (2005) Comparison of behavioral responses to a novel environment between three teleosts, bluegill Lepomis macrochirus, crucian carp Carassius langsdorfii, and goldfish Carassius auratus. Fish Sci 71:314-319 